\title{
Green Technology in Textile Industries
}

\author{
Bouazizi Nabil* \\ IUT d'Evreux, Université de Rouen, France
}

*Corresponding author: Bouazizi Nabil, Normandie Univ, UNIROUEN, INSA Rouen, CNRS, COBRA (UMR 6014), 55 rue Saint Germain, 27000 Evreux, France.

Received Date: April 30, 2021

Published Date: May 12, 2021

\begin{abstract}
Today consumers are becoming in urgently need to protect the environment, promoting their goods ecofriendly-labels. Environmentally green are one of the used terms to characterize the no harm and policies on the environment. This paper reviewed the study of green technology in textile industries, which can be used as advanced approach for environment protection. The possible green methods, recently developed in textile production and its impact on the environment are discussed. It was discussed that green textile is strongly accompanied via respect of lifecycle materials, from raw material through the design, production and logistics up to disposal in order to point out important points and parameters for greening the industry. This work provides information related to recent research work on green technology and the available methods in textile industries. Accordingly, the green technology in textile industry can ensure environmental sustainability.
\end{abstract}

Keywords: Green technology; Eco-friendly process; Textile industries; Green textiles

\section{Introduction}

Global pollution and increased awareness are prompting consumers to seek healthier living choices. Today consumers are increasingly health conscious and actively support greener lifestyles. Eco-friendly or green production involves activities such as reducing and recycling. The green system field are devoted in a group of the strategies for energy production and the non-toxic clean products. This technology is able to induce innovation and change in daily life without affecting the green and sustainable environment. In this regard, it is hard to predict how the above technology can be controlled and surrounded.

When the green textile and apparel industry is considered, it is seen that there have not been enough studies conducted in this area. Moore and Ausley presented an example to increase productivity through greener production induced by cooperative stakeholder actions [1]. Wang. et al. used fuzzy logic with the analytic hierarchy process to form a selection (decision-making) model for different green initiatives in the fashion industry [2]. Wu, et al. studied Taiwan's textile and apparel manufacturers and investigated the relationships between green supply chain management drivers organizational support, social capital and government involvement practices green purchasing, cooperation with customers, ecodesign and investment recovery [3]. Zabaniotou and Andreou presented a paper concerning a feasibility study for energy recovery from cotton ginning waste with greenhouse gas emissions reduction in a textile plant located in Northern Greece [4]. Hashem et al. investigated a novel approach for upgrading both the wrinkle free and softness properties of cotton fabrics without adversely affecting their strength properties using ecofriendly finishing regimes [5]. Mirjalili, et al. studied the extraction of dyes from weld using Soxhlet apparatus [6]. Ren developed environmental performance indicators and identified the best achievable values for cotton woven products and wet processing [7]. Wrona investigated popular eco-labels used in different countries all over the world [8]. Koszewska evaluated the importance of socio and Eco certification and labelling for meeting buyers' expectations of textile and clothing products [9]. Atilgan investigated environmental regulations and their effects on the Turkish Textile Industry [10]. He also researched structures concerning eco-labels in EU countries that Turkey is aiming to integrate [11]. As a strategic solution, Eryuruk aimed to 
evaluate a logistic center establishment as a competitive strategy to gain advantages like time, cost and customer satisfaction for Turkish clothing producers in Istanbul, Turkey [12-14].

In this context, environmentally green textile can affect positively the change of the environmental system of textile industry, which is directly in contact with environmental issues. With enhancement of the clothing industry with eco-green and sustainable products, the environmentally green and non-green industry can be differentiated.

Regarding to the interesting role of environment and working conditions of the textile industry, this work based on the recently published paper, and collected from textile today homepage [15].

This study aimed in the possible techniques that can be exploited to improve the overall environment and working conditions of the textile industry. In addition, according to the uses of green technology the young the non-green textile industry can be converted to more sustainable, respecting the ecofriendly environment. By the respect to the definition of green environment, the key role of greening parameters and analyzes of the textile industry and lifecycle are discussed.

\section{Methodology}

The green technology in industrial textile can be enhanced by improving the overall environmental and manipulation area of textile industries with some target to achieve an internationally recognized standard. This work discussed the green properties of textile industry. Green technology was studied in term of greener for textile during its production, utilization and recycling. In addition, this work attempted to discern the significances of green textiles industries in terms of both economic and environmental benefits by proposition of significant solution to find green industries with the low-cost measurement [16].

\section{Results and Discussion}

Through this study, the opportunities to convert textile industry into green textile industry in two phases have been created. By comparing to the cost of producing a garment of nongreen textile industry and the green textile industry, it is expected that production costs are less for green textile. The cost of clothing

Table 1: Estimated global tonnage of fibrous raw materials from agricultural crops [16]

\begin{tabular}{|c|c|c|}
\hline Crop & Plant component & Availability 000 tonnes \\
\hline Cereals & Straw & 218.5 \\
\hline Barley & Straw & 40.8 \\
\hline Oats & Straw & 465.2 \\
\hline Rice & Straw & 739.9 \\
\hline Rye & Straw & 727.3 \\
\hline Wheat & Stalks & Mote \\
\hline Corn & 900 \\
\hline
\end{tabular}




\begin{tabular}{|c|c|c|}
\hline Bast Fibrous Plants* & Straw & $25.0^{*} /$ \\
\hline Seed Grass & Straw & 2 \\
\hline Oil Flax & Straw & 3 \\
\hline Sorghum & Stalks & 104.7 \\
\hline Sugarcane $^{1}$ & Bagasse $^{1}$ & 100.2 \\
\hline
\end{tabular}

In this context, a potential solution can be obtained from the various parts of plants like woody core, bast, leaf, cane, straw from cereals, grass and seed can be used in applications like building materials, particleboards, insulation boards, human food and animal feed. They do not damage the ecosystem; they can grow in different climatic zones and they recycle the carbon dioxide for the atmosphere. These plants can allow a better agricultural balance and contributed to the growing demand from an expanding population for cellulosic pulp in the next millennium. For example, the estimated world-wide production of fibrous raw materials from agricultural crops is provided in Table 1. In addition, a possible source of straw, can be employed as raw materials for applications like composites and energy crops.

\section{Greening the textile industries}

High amount of water is required for textile dyeing industries, which are a serious problem to the ground or natural water sources resulting in depletion of ground water level by 2.700 liters of water to produce one t-shirt (Figure 2). In the dyeing process, textile industries generate the huge toxic effluent containing colors, sodium sulphate, sodium chloride, sodium hydroxide and traces of other salts. After dyeing, washing of garments a huge quantity of polluted water was generated in the environment. After dyeing the wastewater contains higher solids in the range 4-5\% whereas wash water contains only $0.5-1 \%$. At the light of the above facts, a technology is essential to introduce which can process such wastewater and transform it into reusable water. Thus, the textile industries will get the advantage of using the same water in the dying process repeatedly, also, the salt used for dyeing can be reused or sold in the market. The green technology has been able to provide an environmentally friendly product through its production process as well as the greening of an industry [19].

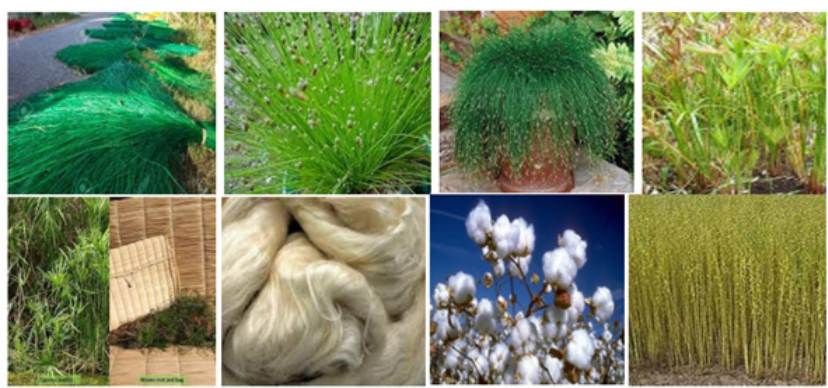

Figure 1: Example of green natural fiber.

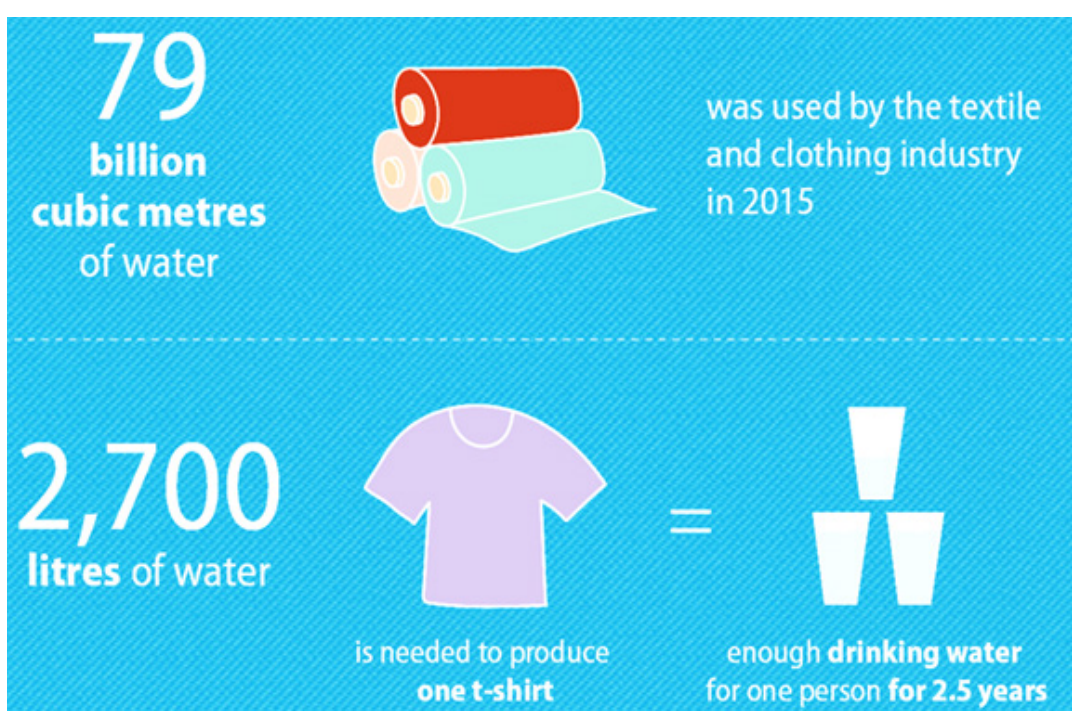

Figure 2: The environmental impact of textile. 


\section{Increases of textile recycling}

The amount of textile products purchased has risen rapidly in the recent years (in the UK consumption has risen by $60 \%$ in the last 10 years, making it the country's fastest growing household waste stream (Figure 3) [20]. The procurement of textile products which are completely or partly made up of recycled fibers is a useful way to effectively address this growing waste problem and the most direct way to limit the impacts described above by limiting the amount of virgin fibers used. In 2008 around $14 \mathrm{~m}$ tones of textile waste were generated in Europe of which $5 \mathrm{~m}$ tones were recovered. About $75 \%$ of this was reused, usually in non-European countries, or recycled, mainly as wipers and in industrial applications [21].

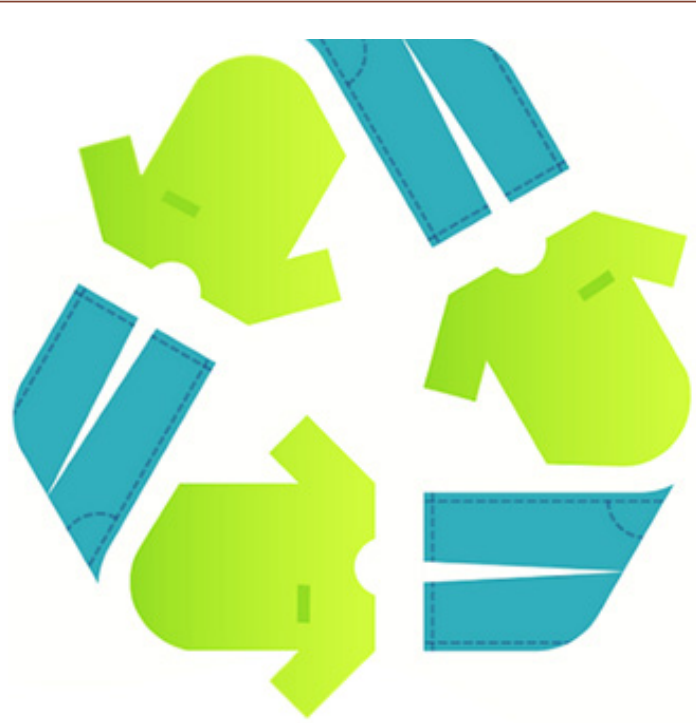

Figure 3: Textile recycling is a great way to greener and limit the environmental pollution.

\section{Economic benefits}

The following economic benefits if non-green industry is converted into green industry.

i. The renowned brands place high importance on the factory environment and working conditions.

ii. The western consumers also prefer buying products manufactured in factories sensitive to the environment. Increase productivity and create brand image.

iii. Though setting up a green factory, it can ensure 30 to
40 percent higher investment than a traditional one; it saves money in the long run for reducing the cost of utility services such as power and water.

iv. Adoption of eco-friendly or green technology initially requires big investments but such initiative could help increase the competitiveness. Buyers usually offer 10 to 15 percent higher prices for eco-friendly products [16-19].

v. The benefits should be very higher as compared to the product costs (Figure 4).

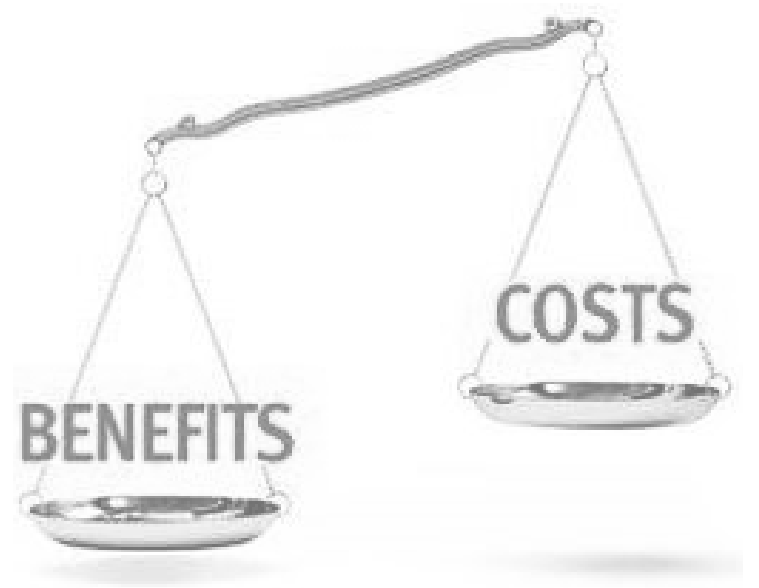

Figure 4: Illustration of textile costs to produce economic benefits. 


\section{Challenge}

Despite the significant economic contribution of the textiles industries in Bangladesh, it has brought in a range of environmental problems mostly pollution of water resources of the country (Figure 5). The main challenge for the textile industry today is to modify production method, so they are eco-friendlier at a competitive price by using safer dyes and chemical and reducing cost of efficient treatment or using disposal system. Thus, its change to textile productions processes affect type and volume of effluent. The lack of a National Effluent Quality Standards and adequate up to date environmental rules and regulations and lack of lands and utility services through economic across [22-24].

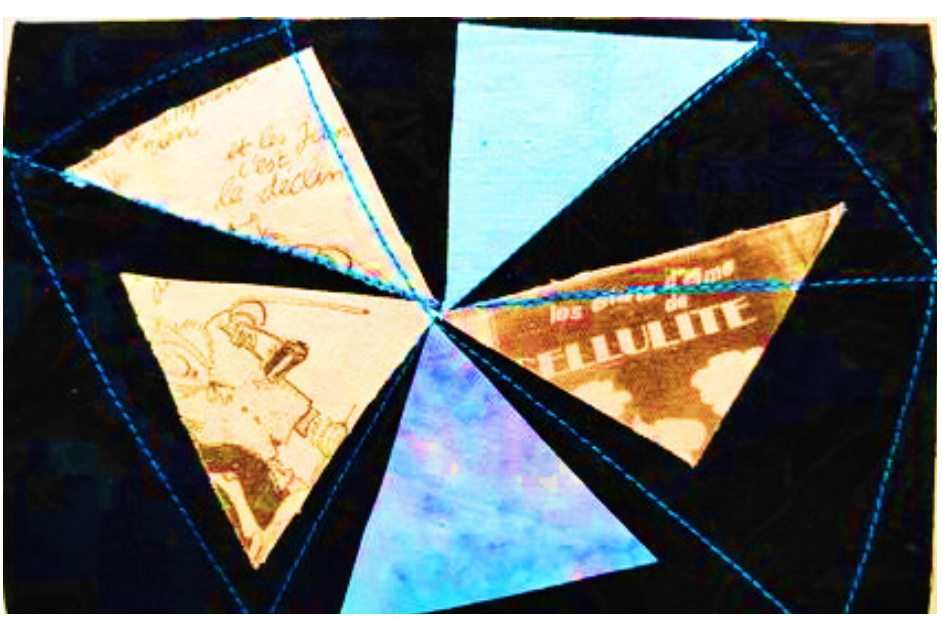

Figure 5: Geometric shapes challenge.

\section{Conclusions}

The aim of this study was to analyze the current situation of textile industry to increase the awareness for making it greener. The competitive environment forces industries to redesign their existing structures is an obligation to be environmentally responsible in the textile industry. In this work, the current green technology was described, which was able to protect the environmental without affecting the textile industries.

As a result, the starting from the product design stage, raw material selection, to the processing and production decisions, transportation, retailing and waste management are the most factors to make textile and clothing production more environmentally friendly.

In addition, this work discussed the recent research work on green technology and the available methods in textile industries. Finally, it was concluded that green technology in textile industry can ensure the ecofriendly and sustainability characters of environment.

\section{Acknowledgment}

We are grateful to the INSA Rouen for its support.

\section{Conflict of Interest}

Author declare no conflict of interest.

\section{References}

1. Moore SB, Ausley LW (2004) Systems thinking and green chemistry in the textile industry: concepts, technologies and benefits. Journal of Cleaner Production 12(6): 585-601.
2. Wang X, Chan HK, Rachel WYY, Rainey ID (2011) A two-stage fuzzyAHP model for risk assessment of implementing green initiatives in the fashion supply chain. International Journal of Production Economics 135(2): 595-606

3. Wu GC, Ding JH, Chen PS (2012) The effects of GSCM drivers and institutional pressures on GSCM practices in Taiwan's textile and apparel industry. International Journal of Production Economics 135(2): 618-636.

4. Zabaniotou A, Andreou K (2010) Development of alternative energy sources for GHG emissions reduction in the textile industry by energy recovery from cotton ginning waste. Journal of Cleaner Production 18(8): 784-790.

5. Hashem M, Ibrahim NA, El-Shafei A, Refaie R, Hauser P (2009) An ecofriendly - novel approach for attaining wrinkle - free/soft-hand cotton fabric. Carbohydrate Polymers 78(4): 690-703.

6. Mirjalili M, Nazarpoor K, Karimi L (2011) Ecofriendly dyeing of wool using natural dye from weld as co-partner with synthetic dye. Journal of Cleaner Production 19(9-10): 1045-1051.

7. Ren X (2000) Development of environmental performance indicators for textile process and product. Journal of Cleaner Production 8(6): 473481 .

8. Wrona ET (2009) Ecolabelling as a Confirmation of the Application of Sustainable Materials in Textiles. Fibres \& Textiles in Eastern Europe $4(75): 21-25$

9. Koszewska M (2011) Social and Eco-labelling of Textile and Clothing Goods as a Means of Communication and Product Differentiation. Fibres \& Textiles in Eastern Europe 19(4): 20-26.

10. Atilgan T (2007) Environmental Regulations in the European Union and their Effects on the Turkish Textile Industry. Fibres \&Textiles in Eastern Europe 15(2): 8-13. 
11. Turan A (2007) Eco-labelling Applications in the Textile \& Apparel Sector in Turkey. Fibres \&Textiles in Eastern Europe 15(2): 14-19.

12. Eryuruk SH (2010) In order to achieve effective logistics activities between textile and clothing sectors site selection and design of a logistics center. Ph.D. Thesis, Istanbul Technical University, Institute of Science and Technology, Turkey.

13. Eryuruk SH, Kalaoglu F, Baskak M (2011) Logistics as a Competitive Strategy: The Analysis of the Clothing Industry in Terms of Logistics. Fibers \& Textiles in Eastern Europe 19(1):12-17.

14. Eryuruk SH, Kalaoglu F, Baskak M (2011) Logistics Center Design for the Turkish Clothing Industry. Fibers \& Textiles in Eastern Europe 19 (5): 17-22.

15. (2016) Textile Today Homepage.

16. Islam T (2017) Assistant Merchandiser, Niagara Textile Ltd, personal communication.

17. (2017) Green Technology Homepage.
18. (2016) International Labor Organization.

19. Mst. Afroja Aktar (2014) Green Insights of Textile Industry in Bangladesh: A Case Study on Mozart Knitting Ltd. Global Disclosure of Economics and Business 3(2).

20. Textiles Recycling Association - Alan Wheeler

21.(2006) Regulation (EC) No $1272 / 2008$ on classification, labelling and packaging of substances and mixtures, amending and repealing Directives 67/548/EEC and 1999/45/EC, and amending Regulation (EC) No $1907 / 2006$.

\section{2. (2017) BGMEA.}

23. Directive 67/548/EEC on the approximation of laws, regulations and administrative provisions relating to the classification, packaging and labelling of dangerous substances.

24. Directive 1999/45/EC concerning the approximation of the laws, regulations and administrative provisions of the Member States relating to the classification, packaging and labelling of dangerous preparations. 